\title{
An Empirical Assessment of Organizational Commitment and Job Performance: Vietnam Small and Medium-Sized Enterprises
}

\author{
BuiNhat VUONG ${ }^{1}$, DaoDuyTUNG$^{2}$ NguyenDinh HOA $^{3}$, \\ Nguyen Thi Ngoc CHAU ${ }^{4}$, Hasanuzzaman TUSHAR ${ }^{5}$
}

Received: April 12, 2020 Revised: April 25, 2020 Accepted: May 07, 2020

\begin{abstract}
Research on employee commitment to the organization is necessary for human resource management, and the result is applied in practice to improve organizational effectiveness. The aim of the present study is to explore factors affecting organizational commitment at the small and medium-sized enterprises (SMEs) in Vietnam. Besides, the relationship between organizational commitment and job performance is examined as well. The research was conducted on a sample consisting of 67 white-collar workers and 260 blue-collar workers at SMEs. A total of 327 valid complete questionnaires were input into SPSS 20 database for processing to provide evidence. The research model and hypotheses were tested using the technique of the hierarchical multiple regression analysis. The research results revealed that income, reward and welfare, direct manager, working environment, coworker, and promotion opportunity tended to associate positively with organizational commitment. Besides, the finding also showed that, when the employee has a high organizational commitment, it would lead to high job performance. The main findings of this study provided some managerial implications for SMEs, in general, and managers, in particular. It implies that Vietnam's small and medium-sized enterprises should improve these six factors to retain employees as well as enhance their job performance.
\end{abstract}

Keywords: Organizational Commitment, Job Performance, SMEs, Working Environment, Promotion Opportunity.

JEL Classification Code: M10, M52, M54

\section{Introduction}

The organization is managed and built up by human beings and it will not have existed without human beings.

${ }^{1}$ First Author and Corresponding Author. Lecturer, Faculty of Labor Relations and Trade Unions, Ton Duc Thang University, Vietnam [Postal Address: No.19, Nguyen Huu Tho Street, Tan Phong Ward, District 7, Ho Chi Minh City, 756600, Vietnam]

Email: nhatvuonga1@gmail.com

${ }^{2}$ Lecturer, Faculty of Business Administration, Tay Do University, Vietnam. Email: howie@tungdao.net

${ }^{3}$ Dean, Faculty of Labor Relations and Trade Unions, Ton Duc Thang

University, Vietnam. Email: nguyendinhhoa@tdtu.edu.vn

${ }^{4}$ Deputy Branch Director, HungCa company, Vietnam.

Email: ngocchau1501@gmail.com

${ }^{5}$ Assistant Professor, College of Business Administration, International University of Business Agriculture and Technology, Bangladesh. Email: tushar@iubat.edu

(c) Copyright: The Author(s)

This is an Open Access article distributed under the terms of the Creative Commons Attribution Non-Commercial License (http://Creativecommons.org/licenses/by-nc/4.0/) which permits unrestricted noncommercial use, distribution, and reproduction in any medium, provided the original work is properly cited.
Therefore, no matter what kind of organization is, to achieve success in its operations, the role of the human factor should be emphasized. Indeed, some researchers (e.g., Giao, Vuong, \& Tung, 2020) stated that if people want to go far they should go with a partner. Also, if managers want to develop a sustainable organization, they also should have the good partner. People may not be able to do any productive work if they are alone in life. For a business, no matter how talented a leader is, if there is no good and loyal employee who is together contributing to the organization, the leader will be exhausted and his greatness cannot succeed in operating the organization. Therefore, employee's commitment to the organization is considered as the key to the sustainable development of an organization. As none of the big or even small organizations can win in the long-run if business is without energetic employees who believe in the company's mission and know how to achieve it. So, the administrators should have partners who are ready to face challenges as well as overcome difficulties. Let's imagine how an organization will survive if the change in human 
resources happens regularly. Besides, the organizations bear the loss of recruiting new employees (former employees bring values that belong to human capital, knowledge, skills, and know-how of the organization when they left), the change also affects the psychology of the staying employees in the organization. The author assumes that these changes will bring negative effects to those employees. They feel insecure, depressed when witnessing their co-workers are slowly quitting, and that will affect their efficiency work.

The small and medium-sized enterprises (SMEs) have existed for hundreds of years and became the heart of the modern economy. In recent years, with development and globalization, workforce demand is rising. The SMEs also encounter many challenges in the workforce competency environment. In hard times, SMEs want their experienced and talented employees to stay on to share difficulties and possess a strong commitment to serving customers for the business interest. Lamba and Choudhary (2013) stated that organizational commitment is the individual's psychological attachment to the organization among its employees. It plays a vital role in attracting and keeping the genius. It may attract and retain staff to have longer tenure. So, committed staff is valuable human capital for the SMEs. Harter et al. (2002) also suggested that organizational commitment is important for meaningful business result. Due to the increasingly competitive business environment, committed workforce has now become a matter of survival for every organization.

To evaluate quality workforces, job performance is an important criterion for the outcomes and success of employees. Job performance leads to the performance of any organizations including SMEs. Employee's job performance is according to their level of motivation, which encourages them to come to work regularly, work diligently, and flexibly. Besides, the level of motivation also helps employees be willing to carry out the necessary tasks. When the employees are not committed to their organization, they will perform at their lowest. This research will concentrate on SMEs' employees, how much they are committed to their work and what level of performance they are giving in their designated position. It will help managers to understand the potential aspects that would lead to better performance and factors, which would lead to a high commitment of employees with the organization. Therefore, it is necessary for SMEs' managers to investigate factors that affect organizational commitment and job performance of their employees.

\section{Literature Review}

\subsection{Organizational Commitment}

Organizational commitment is the intention of long-term engagement with the organization because the commitment of each individual is not simply a matter of the individual, it is a link in the chain of dedicated working to achieve the organizational goals. Until now, there have been a lot of the different views and opinions of researchers in defining employee commitment with the organization. According to Porter et al. (1974), commitment with an organization is a strong belief and acceptance of its goals, a willingness to do their best for the organization and the desire to remain a member of the organization. Commitment with the organization is the willingness to stay at the organization as a member of it, the willingness to endeavor for the organization and support for the company's goals and values (Dubin et al., 1975).

However, Meyer and Allen (1997) argued that organizational commitment is to stay with the organization, to participate in regular work, to work with hard effort every day, to protect assets and believe in the goals of the organization. Cohen (2007) stated that commitment with the organization is the loyalty of employees to the organization, the willingness to try their best for the goals and values of the organization and the desire to be a member of the organization. According to Macey and Schneider (2008), the commitment with the organization is the willingness to work actively for the organization, feeling proud of being a member of the organization and having a strong attachment to the organization. Therefore, the employee's commitment with the organization is a psychological state showing the engagement of an individual to an organization, to a career; it is the loyalty and enthusiasm in employee's work for the organization; it is the willingness to do their best for the organization, always placing the organization's benefits above the benefits of themselves. Individuals who have a higher level of commitment with the organization will be more satisfied with their work, think less about leaving and working for another organization.

Furthermore, organizational commitment has been measured with many different scales. Meyer and Allen (1997) proposed three components of commitment with the organization: Affective commitment: refers to the sentimental commitment, close bond and devote all heart and soul on the organization of employee. Continuance commitment: employees realize they have to pay high costs (opportunity costs) if they leave an organization; Normative commitment: reflects commitment based on the employees' obligations to the organization. This definition is most commonly accepted and used in current studies.

\subsection{Job Performance}

Borman and Motowidlo (1993) defined "job performance as work-related behaviors that can be measured by the individual's level of contribution toward meeting organizational goals. Job performance measures whether a person performs a job well". Daniels and Harris 
(2000) defined "job performance in terms of whether employees' behaviors contribute to organizational goals". Job performance can be defined as an employee's ability to accomplish tasks assigned to him or her in an organizational context. Razek (2011) mentioned that "job performance is one of the most important activities that reflect both the goals and the means necessary to achieve them and represents the specialist efficiency or an organization's achievement expectation. It is the effort made by the employee within the organization to achieve a particular goal. The actual results that companies desire objectively measure". Yang and Kim (2018) indicated that the extent to which a member has successfully performed his or her job is one of the indicators of organizational effectiveness. Briefly, job performance indicates the effectiveness of the employee's specific actions that contribute to attaining organizational goals.

\section{Hypotheses Development}

\subsection{Income}

According to Armstrong and Taylor (2017), income is a payment for a job, and it can have many different forms including basic wages, additional wages paid in cash, such as shift payments, overtime payments, and welfare. However, Dessler (2019) stated that income is a financial and nonfinancial payment that employer has to pay for employees by the time, skills, and efforts spending to complete their job and achieve the organizational goals. According to a survey on the actual situation of human resource management in Vietnamese enterprise, the cause of employees' quitting for the income accounts for nearly $40 \%$. In another study by VietnamWorks (2018), 24\% of respondents also said that the main reason they are looking for new jobs is because of their income. Once satisfied with the income, employees will want to be more committed to the organization, more devotion to the organization. Therefore, hypothesis $\mathrm{H} 1$ is proposed as below:

$\mathrm{H}_{1}$ : Income positively affects the commitment of employees with the organization.

\subsection{Reward and Welfare}

The reward is a recognition, honor of merit and encouragement with material benefits or spiritual benefits for individual and collective who have good achievements in the organization. Rewarding the right people, the right jobs in time can motivate and promote the commitment of employees with the organization. Welfare is the indirect remuneration that is paid in the form of life support for employees. The amount is called a bonus, it is paid equally to employees regardless of their work results such as "bonus" on holidays, "13th-month salary" ... which is essentially welfare. All employees want to be rewarded for their devotions or contributions in certain ways. The employees can get in the organization, not just money and not everyone works for money. The money is a strong motivating factor for low-skilled workers and those people who desire material well-being, but it has a little effect on those who prefer to complete challenging jobs. Therefore, the reward must aim towards the satisfaction of the individual needs of workers. Besides, the reward commensurate with the contribution, the diversity in welfare policies will show the cares of the employers to employees, making employees feel satisfied with the reward and welfare policy of the organization. Once satisfied with the reward and welfare policy, the strength of the employees' commitment to the organization will be tighter than ever. Therefore, hypothesis $\mathrm{H} 2$ is proposed as follows:

$\mathrm{H}_{2}$ : The reward and welfare policy positively affects employees' commitment to the organization.

\subsection{Working Environment}

The working environment in an organization includes a material environment and psychological environment ( Islam, Bangish, Muhammad, \& Jehan, 2016). The material environment includes workplace location, working space, and working conditions. The material environment that is suitable and comfortable will certainly create great conditions for employees to increase their commitment to the organization. The psychological environment includes working pressure, working atmosphere, etc. A working environment that is friendly, happy, sociable will increase the confidence of each employee, stimulate creativity and increase the cohesion of employees with the organization. According to Armstrong and Taylor (2017), once the organization has a great working environment, the employee's commitment to the organization is continually rising. Hanaysha (2016) showed the relationship between the working environment and employee's commitment to the organization. The working environment is always of concern by employees because of personal convenience, and it is also a factor that helps them fulfill their tasks. A good working environment will further enhance the commitment of employees with the organization. Therefore, hypothesis $\mathrm{H} 3$ is proposed as follows:

$\mathrm{H}_{3}$ : The working environment positively affects an employee's commitment to the organization.

\subsection{Coworker}

Coworker support is the feeling related to the behaviors and relationships with other peers at work. Collaboration 
and support for each other at work or competition and lack of enthusiasm in cooperation also affect the commitment of employees. Coworker is whom we meet more often than both family members and friends. Therefore, the support and respect of coworkers are always positive factors in success at work. Suma and Lesha (2013) showed the existence of the relationship between coworkers and employee's commitment to the organization in their study. If employees work in an organization with good coordination, affection, and mutual support among their coworkers, it will make employees feel happy and they will commit higher with the organization. Therefore, hypothesis H4 is proposed as follows:

$\mathrm{H}_{4}$ : Coworker positively affects an employee's commitment to the organization.

\subsection{Direct Manager}

The direct manager is the person responsible for administering, managing, assigning jobs, training, supervising and developing the successive employees. The company may have a good working environment, compensation, welfare or good remuneration policies for its employees, but a mediocre manager can disable these advantages and increase dissatisfaction for employees. According to the research of Dessler (2019), employees who have a good relationship with their direct managers have a higher commitment to the organization. Armstrong and Taylor (2017) argued that the direct manager is an important premise of employee commitment with the organization. According to Talukder (2019), the direct manager is seen as the path leading to the commitment of employees with the organization. Hypothesis H5 is proposed as follows:

$\mathrm{H}_{5}$ : Direct manager positively affects an employee's commitment to the organization.

\subsection{Promotion Opportunity}

Promotion is the progress of upping expertise, rank, and position in the job. Promotion opportunity is understood as career advancement, which means that the manager acknowledges the ability and struggle of an employee, not just because of the relationship. Promotion is the goal of the employee when starting a job. However, to achieve that it's too difficult. Promotion opportunity contributes to the stimulation of employee to make efforts in their work, they will try their best to achieve their promotion goals. The organization with a specific training and promotion road will push employee's commitment to the organization higher and higher. According to Giao, Vuong, and Tung (2020), once the organization provides training and promotion opportunities that make employees feel that the organization appreciates them, and this increases their commitment to the organization. Therefore, hypothesis H6 is proposed as follow:

$\mathrm{H}_{6}$ : Promotion opportunity positively affects employees' commitment to the organization.

\subsection{Organizational Commitment and Job Performance}

The literature shows a wide range of evidence supporting the relationship between organizational commitment and job performance. Specifically, the findings of the previous study (e.g., Raja Nabeel-Ud-Din et al., 2019; Sungu et al., 2019; Vuong \& Arthachinda, 2019) indicated that organizational commitment was a significant predictor of job performance. Therefore, hypothesis $\mathrm{H} 7$ is proposed as follows:

$\mathrm{H}_{7}$ : Organizational commitment impacts positively on job performance among employees at SMEs in Vietnam.

Figure 1 shows the conceptual model of this study.

\section{Research Results}

\subsection{Data Description}

The study was based on a survey of employees who are working at SMEs in Vietnam. A total of 400 questionnaires

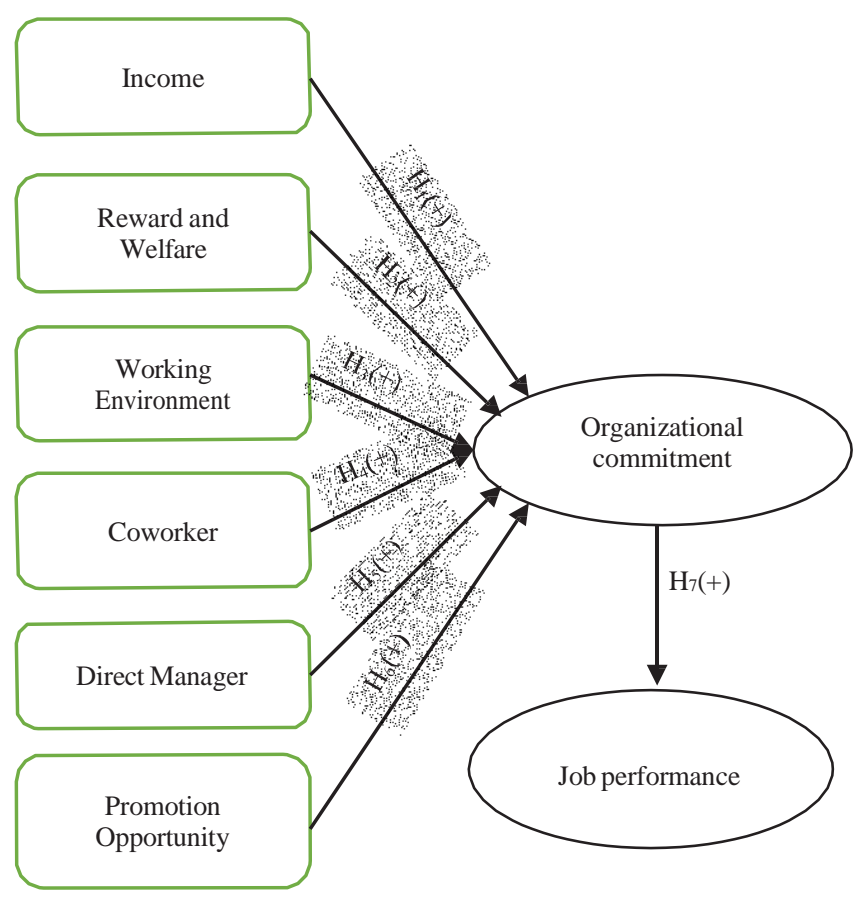

Figure 1: The conceptual model 
were distributed and 350 questionnaires were taken back; after eliminating unsatisfactory questionnaires, there remained 327 valid questionnaires, reaching $81.75 \%$. The questionnaire was coded and put into data processing by using SPSS 20.0 software. The author classified 327 surveyed employees by gender, age, education level, working time, position/rank and income. The result of the demographic is presented in Table 1.

\subsection{The Reliability and Validity of the Scale}

The scale will first be analyzed Cronbach's Alpha reliability coefficient, variables with an item-total correlation less than 0.3 will be rejected and the scale is accepted for analysis in the following steps when Cronbach's Alpha reliability is from 0.6 and above (Vuong \& Suntrayuth, 2020). In Table 2, the analysis results show that the value of Cronbach's Alpha fluctuates in the range from 0.744 to 0.936, and the smallest total correlation coefficient of each variable is more than 0.3 . Therefore, the scales achieved reliability and will be used to analyze for exploratory factors.

The results of the first exploratory factor analysis prove that KMO and Bartlett's test in the factor analysis showing Sig. $=0.000($ Sig. $=0.000<0.05) ; \mathrm{KMO}$ coefficient reaches $0.757(>0.5)$. This result indicates that the observed variables in the general are correlated with each other and the EFA factor analysis is appropriate. At Eigenvalues are more than 1 and with principal components analysis and varimax rotation, factor analysis extracted 08 factors from 36 observed variables and with a cumulative variance of $66.430 \%$ (more than 50\%) met the requirement. However, the IN5 variable with the disparity between the factor loadings on the first factor and second one is $0.213<0.3$, so the IN5 variable is eliminated from the scale of income (Giao, Vuong, Huan, et al., 2020).

After eliminating the IN5 item, the author proceeded to analyze the exploratory factor for the second time (see Table 3).

Table 1: Demographic statistics

\begin{tabular}{|c|c|c|c|c|c|}
\hline & & White-collar worker & Blue-collar worker & Total & Frequency \\
\hline \multirow[t]{2}{*}{ Gender } & Male & 30 & 90 & 120 & 36.7 \\
\hline & Female & 37 & 170 & 207 & 63.3 \\
\hline \multirow[t]{2}{*}{ Age } & Under 30 & 33 & 217 & 250 & 76.5 \\
\hline & $30-55$ & 34 & 43 & 77 & 23.5 \\
\hline \multirow[t]{3}{*}{ Education level } & Under High School & 0 & 260 & 260 & 79.5 \\
\hline & Colleges/ Universities & 64 & 0 & 64 & 19.6 \\
\hline & Graduate & 3 & 0 & 3 & 0.9 \\
\hline \multirow{3}{*}{$\begin{array}{l}\text { Working } \\
\text { time }\end{array}$} & $<3$ years & 29 & 160 & 189 & 57.8 \\
\hline & $3-5$ years & 10 & 90 & 100 & 30.6 \\
\hline & $>5$ years & 28 & 10 & 38 & 11.6 \\
\hline \multirow{3}{*}{$\begin{array}{l}\text { Income } \\
\text { (VND) }\end{array}$} & $<5$ million & & 13 & 13 & 3.4 \\
\hline & 5-10 million & 48 & 247 & 295 & 0.9 \\
\hline & $>10$ million & 19 & 0 & 19 & 16.2 \\
\hline
\end{tabular}

Table 2: The analysis results of reliability

\begin{tabular}{|l|c|c|c|}
\hline \multicolumn{1}{|c|}{ Scale } & Number of items & Cronbach's alpha & Smallest item-total correlation \\
\hline Income & 5 & 0.936 & 0.773 \\
\hline Reward and welfare & 5 & 0.906 & 0.699 \\
\hline Working environment & 5 & 0.839 & 0.602 \\
\hline Coworker & 4 & 0.846 & 0.569 \\
\hline Direct manager & 5 & 0.794 & 0.513 \\
\hline Promotion opportunity & 4 & 0.744 & 0.374 \\
\hline Organizational commitment & 4 & 0.852 & 0.608 \\
\hline Job performance & 4 & 0.822 & 0.560 \\
\hline
\end{tabular}


Table 3: The second time results of EFA

\begin{tabular}{|c|c|c|c|}
\hline Variables & Items & Code & Factor loading \\
\hline \multirow{5}{*}{$\begin{array}{l}\text { Reward and } \\
\text { welfare }\end{array}$} & My achievements are recognized promptly by my superior & RW3 & 0.905 \\
\hline & I am rewarded with my contributions & RW4 & 0.878 \\
\hline & The company has a clear reward policy & RW2 & 0.855 \\
\hline & The corporate welfare regime is attractive & RW5 & 0.764 \\
\hline & The benefits I receive are not inferior to other companies & RW1 & 0.706 \\
\hline \multirow[t]{4}{*}{ Income } & My current income corresponds to my competencies & IN2 & 0.949 \\
\hline & I can live off your current income & IN1 & 0.860 \\
\hline & The income in my company is very fair for the positions & IN3 & 0.836 \\
\hline & I understand the income policy of my company & IN4 & 0.833 \\
\hline \multirow[t]{5}{*}{ Coworker } & My colleagues are very friendly & $\mathrm{CO} 2$ & 0.871 \\
\hline & People always work together to get things done. & $\mathrm{CO} 3$ & 0.854 \\
\hline & Colleagues are ready to assist me in my work & $\mathrm{CO} 4$ & 0.785 \\
\hline & My colleagues are often willing to share work experience with me & CO1 & 0.705 \\
\hline & My colleagues are reliable & CO5 & 0.702 \\
\hline \multirow{5}{*}{$\begin{array}{l}\text { Working } \\
\text { environment }\end{array}$} & I am provided with sufficient equipment to work & WE1 & 0.828 \\
\hline & Policies and procedures related to me in the company are fully informed & WE3 & 0.818 \\
\hline & I feel comfortable working at the company & WE5 & 0.748 \\
\hline & $\begin{array}{l}\text { The company creates conditions for me to express my individual } \\
\text { competencies }\end{array}$ & WE2 & 0.745 \\
\hline & I am provided with sufficient equipment to work & WE4 & 0.743 \\
\hline \multirow{5}{*}{$\begin{array}{l}\text { Direct } \\
\text { manager }\end{array}$} & I can communicate freely with my direct manager & $\mathrm{DM} 3$ & 0.775 \\
\hline & I am often encouraged at work by my direct manager & DM5 & 0.772 \\
\hline & I always get the guidance of my direct manager when needed & DM1 & 0.747 \\
\hline & I am trusted in your work & DM4 & 0.701 \\
\hline & The direct manager always cares for me & DM2 & 0.687 \\
\hline \multirow{4}{*}{$\begin{array}{l}\text { Promotion } \\
\text { opportunity }\end{array}$} & I have many promotion opportunities at the company & $\mathrm{PO} 4$ & 0.760 \\
\hline & My company has specific promotion policies and conditions & $\mathrm{PO} 2$ & 0.697 \\
\hline & $\begin{array}{l}\text { My company always creates equal promotion opportunities for competent } \\
\text { people }\end{array}$ & PO1 & 0.661 \\
\hline & I am satisfied when I have the opportunity to advance & PO3 & 0.631 \\
\hline \multirow[t]{4}{*}{$\begin{array}{l}\text { Organizational } \\
\text { commitment }\end{array}$} & $\begin{array}{l}\text { I am willing to put in a great deal of effort beyond that normally required in } \\
\text { order to help this organization be successful }\end{array}$ & OC2 & 0.898 \\
\hline & I really care about the fate of this organization & OC4 & 0.857 \\
\hline & I talk up this organization to my friends as a great organization to work for & OC3 & 0.807 \\
\hline & For me, this is the best of all possible organizations for which to work & OC1 & 0.767 \\
\hline \multirow{4}{*}{$\begin{array}{l}\text { Job } \\
\text { performance }\end{array}$} & I adequately complete assigned duties & JP2 & 0.871 \\
\hline & I fulfill responsibilities specified in the job description & JP3 & 0.855 \\
\hline & I Perform tasks that are expected & JP1 & 0.736 \\
\hline & I meet formal performance requirements of the job & JP4 & 0.734 \\
\hline
\end{tabular}


The analysis results show that the cumulative variance reaches $66.22 \%$ (more than $50 \%$ ). KMO coefficient reaches 0.734 (more than 0.5 and less than 1). Bartlett's test has Sig. $=0.000$ (less than 0.05). The eigenvalue coefficient reaches 1.784 (more than 1). These indicators met the requirements and the factor loading of the observed variables was more than 0.5. Therefore, the scale met the requirements of validity.

\subsection{Hypothesis Testing}

Before conducting a regression analysis, the author uses the Pearson correlation coefficient to quantify the close level of the linear relationship between the independent variable and the dependent variable (Vuong \& Giao, 2020). In the Pearson correlation analysis, there is no distinction between independent and dependent variables, all variables are considered equally. However, if the variables closely correlate, the multicollinearity issue must be considered after regression analysis.

In Table 4, the correlation analysis results showed that the significance of the coefficients is very small (sig. < 0.05), so the correlation coefficients were statistically significant and were eligible to put into regression analysis. Based on the independent and dependent variables that have been considered linear correlation, the author continued using multiple regression analysis to find the relationship between these concepts.

The adjusted R Square value of 0.729 meant that $72.9 \%$ of the variation of the organizational commitment was explained by the variation of six independent variables. Moreover, the adjusted R Square value of job performance was 0.317 which indicated that $31.7 \%$ of the variation of job performance was explained by the organizational commitment.
The $\mathrm{F}$ test uses in variance analysis (Anova) is a hypothesis test for the suitability of the general linear regression model. In Table 5, the F value with Sig. $=0.000$ $(<0.05)$ meant the linear regression model was consistent with the actual data collected and the included variables were statistically significant at the 5\% significance level. Also, the Durbin - Watson test showed that $d=1.944(1<d<3)$, it showed the residuals were independent of each other or not be correlated between the residuals. Moreover, Variance Inflation Factor (VIF) reached the maximum value of 2.356 (less than 5) showing that these independent variables were not closely related to each other, so there was no happening multicollinearity (Vuong et al., 2020).

Regression coefficients have positive signs (+), which showed that independent variables were positively associated with dependent variables. Employee's commitment with the organization (OC) was impacted the strongest and in descending order of impact: income $(\beta=0.584)$, reward and welfare $\left(\beta_{2}=0.347\right)$, direct manager $\left(\beta_{5}=0.216\right)$, working environment $\left(\beta_{3}=0.177\right)$, coworker $\left(\beta_{4}=0.158\right)$, and promotion opportunity $\left(\beta_{6}=0.1127\right)$. Furthermore, hypothesis 7 predicted a positive relationship between organizational commitment and job performance. The result showed that these two variables are positively related, and it is statistically significant $\left(\beta_{7}=0.137\right)$. Therefore, all hypotheses were supported.

\section{Conclusion and Recommendations}

\subsection{Conclusion}

The research results showed that six factors positively affected organizational commitment. All scales used in the research were reliable and valid. The research showed that these

Table 4: Matrix correlation coefficient

\begin{tabular}{|c|c|c|c|c|c|c|c|c|}
\hline & IN & RW & WE & $\mathrm{CO}$ & DM & PO & OC & JP \\
\hline IN & 1 & $.141^{*}$ & .025 & $.193^{* *}$ & .062 & .077 & $.036^{*}$ & $.533^{* *}$ \\
\hline RW & & 1 & $.179^{* *}$ & .061 & .089 & .005 & $.142^{*}$ & $.286^{* *}$ \\
\hline WE & & & 1 & .108 & .033 & .049 & $.084^{*}$ & $.205^{* *}$ \\
\hline $\mathrm{CO}$ & & & & 1 & $.212^{* *}$ & .031 & $.698^{* *}$ & $.186^{* *}$ \\
\hline DM & & & & & 1 & .072 & $.024^{* *}$ & $.183^{* *}$ \\
\hline PO & & & & & & 1 & $.088^{*}$ & $.104^{*}$ \\
\hline OC & & & & & & & 1 & $.075^{\star *}$ \\
\hline JP & & & & & & & & 1 \\
\hline \multicolumn{9}{|c|}{$\begin{array}{l}\text { Note: } \mathrm{IN}=\text { Income; } \mathrm{RW}=\text { Reward and welfare; } \mathrm{WE}=\text { Working environment; } \mathrm{CO}=\text { Coworker; } \mathrm{DM}=\text { Direct manager; } \mathrm{PO}=\text { Promotion } \\
\text { opportunity; } \mathrm{OC}=\text { Organizational commitment; } \mathrm{JP}=\text { Job performance. } \\
{ }^{*}=\mathrm{p}<0.05 ;{ }^{* *}=\mathrm{p}<0.01\end{array}$} \\
\hline
\end{tabular}


Table 5: Statistical analysis of regression coefficients

\begin{tabular}{|c|c|c|c|c|c|}
\hline \multirow[t]{2}{*}{ Hypothesis } & \multirow[t]{2}{*}{ Variable } & Model 1 & Model 2 & \multirow[t]{2}{*}{ VIF } & \multirow[t]{2}{*}{ Result } \\
\hline & & OC & JP & & \\
\hline $\mathrm{H}_{1}$ & IN & $0.584^{* * *}$ & & 1.126 & Accepted \\
\hline $\mathrm{H}_{2}$ & RW & $0.347^{* \star \star}$ & & 1.101 & Accepted \\
\hline $\mathrm{H}_{3}$ & WE & $0.177^{\star \star \star}$ & & 1.046 & Accepted \\
\hline $\mathrm{H}_{4}$ & $\mathrm{CO}$ & $0.158^{\star \star}$ & & 2.356 & Accepted \\
\hline $\mathrm{H}_{5}$ & $\mathrm{DM}$ & $0.216^{\star \star \star *}$ & & 1.120 & Accepted \\
\hline $\mathrm{H}_{6}$ & $\mathrm{PO}$ & $0.127^{\star *}$ & & 1.041 & Accepted \\
\hline $\mathrm{H}_{7}$ & $\mathrm{OC}$ & & $0.137^{*}$ & 2.197 & Accepted \\
\hline \multicolumn{2}{|l|}{ Adjusted R Square } & 0.729 & 0.317 & & \\
\hline \multicolumn{6}{|c|}{$\begin{array}{l}\text { Sig. of ANOVA }=0.000 \\
\text { Durbin-Watson }=1.944\end{array}$} \\
\hline \multicolumn{6}{|c|}{$\begin{array}{l}\text { Note: } \\
\text { IN = Income; } \mathrm{RW}=\text { Reward and welfare; } \mathrm{WE}=\text { Working environment; } \mathrm{CO}=\text { Coworker; } \mathrm{DM}=\text { Direct manager; } \\
\mathrm{PO}=\text { Promotion opportunity } \mathrm{OC}=\text { Organizational commitment; JP = Job performance. } \\
{ }^{* * *}=\mathrm{p}<0.0001 ;{ }^{* *}=\mathrm{p}<0.01 ;{ }^{*}=\mathrm{p}<0.05\end{array}$} \\
\hline
\end{tabular}

six factors have a positive relationship with the employee's commitment to the organization, are arranged in descending order: income, reward and welfare, direct manager, working environment, coworker, and promotion Opportunity. Besides, the find indicated that organizational commitment positively impacted job performance (see Figure 2).

\subsection{Recommendations}

\subsubsection{Income}

"Income" is the factor that has the greatest impact on the commitment of employees at SMEs (mean $=4.08)$. The companies need to build a payroll with specific standards and requirements for each position; they need to evaluate the right role of each employee so that they can receive income levels commensurate with their dedication and reasonable. For the blue-collar worker, the workforce often fluctuates, leaves work (due to illness, accident, low wages, unfair treatment), the companies should have a special salary policy and regime for them to encourage them to keep on working hard and committing with the company. In fact, there are many cases of employees who are recruited later, have lower education levels but received higher salary levels or are the same seniority but some people have wage increase and some do not, these cases are more or less causing discontent for employees. Therefore, to do this, companies need a job description for each specific position. With a specific job description, each employee will know their position, role, and contribution as well as of other members'. As a result, they will find themselves paid fairly and proportionately.

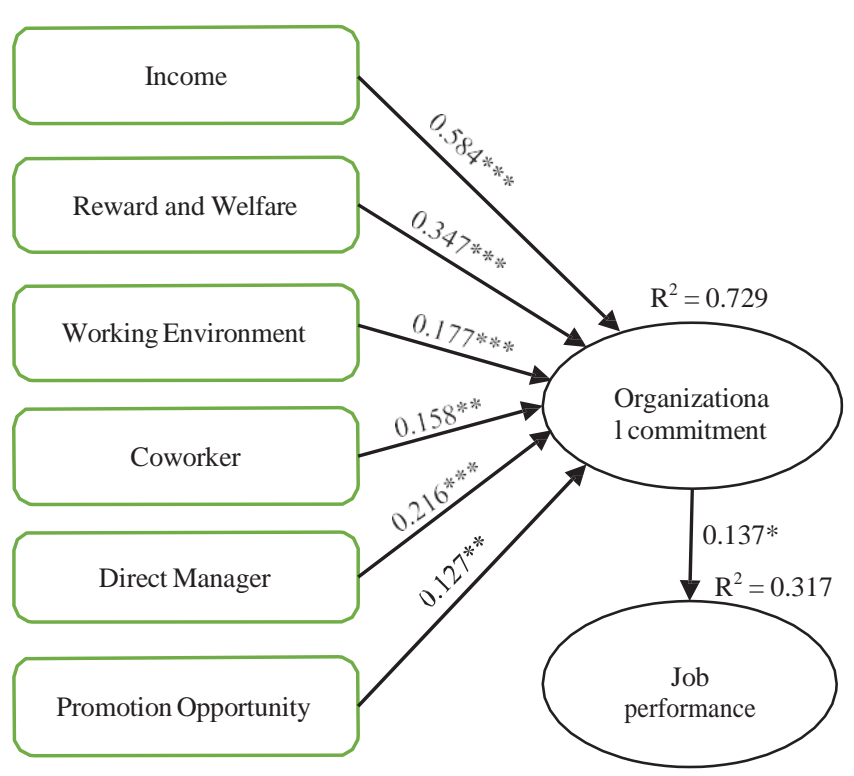

Figure 2: The resulting model

\subsubsection{Reward and Welfare}

"Reward and welfare" is the factor that has the second impact on the commitment of employees at SMEs (mean = 4.35). The companies should through accurate assessments and fair evaluations to ensure fairness for employees. The companies should associate the reward increase with the 
development of the company so that employees understand that only when the company thrives, their reward and welfare is constantly enhanced. The reward policy can change according to the actual situation of the company. Therefore, the companies should clearly announce the reward as well as the specific reward calculation for each division before the employee receives it. For rewarding the achievements, the companies should stipulate in specific which cases are recorded for individual, which cases are recorded for the collective to avoid dissatisfaction and envy between employees.

\subsubsection{Direct Manager}

"Direct manager" is the factor that has the third impact on the commitment of employees at SMEs (mean $=3.54$ ). The analysis results showed that there is still a distance between the direct manager and employees. The direct manager should create closeness and create a friendly working atmosphere. By doing so, the employee can confidently present opinions and ideas as well as present ways to solve their problems when any problem arises. At the same time, through the closeness, the direct manager can understand the feelings and aspirations of employees to have attention, encouragement, sharing for employees on time and timely. Employees hope that the direct manager gives them trust in work. Once trusting employees, the direct manager will be completely assured of assigning jobs without having to worry whether the employee does wrong or reveal a company's secret for competitors or not. The direct manager should base on the strengths and weaknesses of each employee to assign a suitable job for them. In this way, the employees feel that they are an important part of the organization and willing to devote themselves to the organization.

\subsubsection{Working Environment}

"Working environment" is the factor that has the fourth impact on the commitment of employees at SMEs (mean = 3.76). The companies should invest the equipment for employees more fully and timely. For example, the company's computer system is quite old, but the company has not upgraded yet. Therefore, the work of employees is often interrupted by the cause of a computer's issue. Besides, the company should install warehouse management software: materials, packaging, goods, at the same time, should train the employee to implement this software. For goods input and output areas, the company should install a high-quality camera system to record the input and output activities in detail to provide customers with evidence in case they request. In addition, the companies should regularly organize the training courses for workers on labor safety, using machines and equipment.

\subsubsection{Coworker}

"Coworker" is the factor that has the fifth impact on the commitment of employees at SMEs (mean = 3.73). The companies should build collective goals, build and consolidate the spirit of cooperation, supporting each other by encouraging employees to work as teamwork, by dividing the task according to teamwork and evaluating the results according to teamwork. At that time, employees not only try to complete their tasks but also help coworkers in their work. At the same time, with the office division, the companies should organize information-sharing meetings between departments so that employees can understand each other's work better and identify the problems to support each other to complete the job.

\subsubsection{Promotion Opportunity}

"Promotion opportunity" is the factor that has the weakest impact on the commitment of employees at SMEs (mean $=4.12)$. The companies should focus on planning and creating the development of career opportunities for employees. This requires that the board of directors supplies closely guidance to the departments, production departments to evaluate, review the orientation, development planning for each individual in the department. At the same time, the company should determine the career promotion roadmap for employees through the promotion flowcharts of each specific position title. Understanding the employees' thoughts, aspirations and transmitting criteria of a development opportunity is essential for employees to be aware and have motivation, so that they strive to achieve promotion targets in their career. Especially, the companies should prioritize internal promotion. In case, the promoted employees still do not have enough experience to handle the work at the new position, the companies should give them more time to challenge as well as time for them to train their bravery.

\section{Limitations of the Research}

Although the research has completed the stated objectives, there are still some limitations. Firstly, the research subjects are employees who are working at SMEs including white-collar workers and blue-collar workers. However, the research only uses one research model for both subjects, so the difference in the commitment with the company between these two subjects has not been shown. Therefore, further research should have a separate model for each object to show the difference in commitment with the company between white-collar workers and blue-collar workers. Secondly, the researchers used the convenient sampling method, so the representativeness is not high. Therefore, further research should employ probability sampling methods to collect data from SMEs. 


\section{References}

Armstrong, M., \& Taylor, S. (2017). Handbook of Human Resource Management Practice. London, UK: Kogan Page Ltd

Borman, W. C., \& Motowidlo, S. M. (1993). Expanding the criterion domain to include elements of contextual performance. Personnel Selection in Organizations, 1(5), 71-73.

Cohen, A. (2007). Commitment before and after: an evaluation and reconceptualization of organizational commitment. Human Reseurce Management Review, 17, 336-354.

Daniels, K., \& Harris, C. (2000). Work, psychological well-being andpevfovmance. Occupational Medicine, 50(5), 304-309.

Dessler, G. (2019). Fundamentals of Human Resource Management (5th Ed.). Upper Saddle River, NJ: Pearson.

Dubin, R., Champoux, J., \& Porter, L. (1975). Central life interests and organizational commitment of blue-collar and clerical workers. Administrative Science Quarterly, 20(3), 411- 421.

Giao, H. N. K., Vuong, B. N., Huan, D. D., Tushar, H., \& Quan, T. N. (2020). The effect of emotional intelligence on turnover intention and the moderating role of perceived organizational support: Evidence from the banking industry of Vietnam. Sustainability, 12(5), 1857. https://doi.org/10.3390/su12051857

Giao, H. N. K., Vuong, B. N., \& Tung, D. D. (2020). A Model of Organizational Culture for Enhancing Organizational Commitment in Telecom Industry: Evidence from Vietnam. WSEAS Transactions on Business and Economics, 17, 215-224. doi:10.37394/23207.2020.17.23

Islam, Z., Bangish, S. B., Muhammad, H., \& Jehan, A. S. (2016). The Impact of HR Practices on Job satisfaction: A Case Study of Hotel Industry in Pakistan. Journal of Asian Finance, Economics and Business, 3(1), 43-48. https://doi.org/10.13106/ jafeb.2016.vol3.no1.43.

Hanaysha, J. (2016). Testing the Effects of Employee Engagement, Work Environment, and Organizational Learning on Organizational Commitment. Procedia - Social and Behavioral Sciences, 229, 289-297.

Harter, J. K., Schmidt, F. L., \& Hayes, T. L. (2002). Business-unitlevel relationship between employee satisfaction, employee engagement, and business outcomes: A meta-analysis. Journal of Applied Psychology, 87(2), 268-279.

Lamba, S., \& Choudhary, N. (2013). Impact of HRM practices on organizational commitment of employees. International Journal of Advancements in Research \& Technology, 2(4), 407423.

Macey, W. H., \& Schneider, B. (2008). The meaning of employee engagement. Industrial and Organizational Psychology: Perspectives on Science and Practice, 1, 3-30.
Meyer, J. P., \& Allen, N. J. (1997). Commitment in the workplace: Theory, research, and application. Thousand Oaks, CA: Sage Publications.

Porter, L. W., Steers, R. M., Mowday, R. T., \& Boulian, P. V. (1974). Organizational commitment, job satisfaction, and turnover among psychiatric technicians. Journal of Applied Psychology, 59(5), 603-609.

Razek, W. A. A. (2011). Factors affecting the effectiveness of the job performance of the specialists working in the youth care at Helwan University. World Journal of Sport Sciences, 4(2), 116-125.

Suma, S., \& Lesha, J. (2013). Job Satisfaction and Organizational commitment: the case of shkodra Municipality. European Scientific Journal, 9, 41-51.

Sungu, L. J., Weng, Q., \& Xu, X. (2019). Organizational commitment and job performance: Examining the moderating roles of occupational commitment and transformational leadership. International Journal of Selection and Assessment, 27(3), 280-290. doi:10.1111/ijsa.12256

Talukder, A. K. M. M. H. (2019). Supervisor Support and Organizational Commitment: The Role of Work-Family Conflict, Job Satisfaction, and Work-Life Balance. Journal of Employment Counseling, 56(3), 98-116. doi:10.1002/ joec. 12125

Vuong, B. N., \& Arthachinda, P. (2019). The effect of transformational leadership on job performance through the mediation of job satisfaction: The case of Vietnamese stateowned organizations. The Korean Association For Public Administration, 161, 519-548.

Vuong, B. N., \& Giao, H. N. K. (2020). The Impact of Perceived Brand Globalness on Consumers' Purchase Intention and the Moderating Role of Consumer Ethnocentrism: An Evidence from Vietnam. Journal of International Consumer Marketing, 32(1), 47-68. https://doi.org/10.1080/08961530.2019.1619115

Vuong, B. N., Hieu, V. T., \& Trang, N. T. T. (2020). An empirical analysis of mobile banking adoption in Vietnam. Gestãoe Sociedade, 14, 3365-3393 https://doi.org/10.21171/ges. v14i37.3078

Vuong, B. N., \& Suntrayuth, S. (2020). The impact of human resource management practices on employee engagement and moderating role of gender and marital status: An evidence from the Vietnamese banking industry. Management Science Letters, 10(7), 1633-1648. https://doi.org/10.5267/j.msl.2019.12.003

Yang, H.-C., \& Kim, Y.-E. (2018). The Effects of Corporate Social Responsibility on Job Performance: Moderating Effects of Authentic Leadership and Meaningfulness of Work. Journal of Asian Finance, Economics and Business, 5(3), 121-132. http:// doi.org/10.13106/jafeb.2018.vol5.no3.121 